\title{
Hydroamination of Terminal Alkynes by Amines Catalyzed by Copper Heteropoly Salts: A Simple Approach Towards Imine Synthesis
}

\author{
Ganapati V. Shanbhag, K. Palraj and S.B. Halligudi*
}

Inorganic Chemistry and Catalysis Division, National Chemical Laboratory, Pune - 411008, India

\begin{abstract}
The hydroamination reaction offers a very attractive route for the synthesis of alkylated amines and their derivatives with no byproduct formation. Heterogeneous intermolecular hydroamination reactions of alkynes with aromatic amines using different inexpensive copper salts of hetropolyacid catalysts were investigated. Among heteropoly salts, copper salts of silicotungstic acid showed highest activity. Reactivity of aromatic amines increased with increase in its basicity. Acidity in heterogeneous catalyst can act as promoter in hydroamination of alkynes.
\end{abstract}

\section{INTRODUCTION}

Hydroamination reaction offers an efficient synthetic route to alkylated amines, enamines and imines by converting readily accessible alkenes and alkynes into desirable, more highly substituted nitrogen-containing products in a single step. Due to the commercial importance of amines, amides, ammonium and alkylammonium salts, ureas, carbamates, isocyanates and amino acids, this reaction have gained considerable importance in synthetic organic and industrial chemistry [1]. The classical method for imine synthesis is amination of aldehydes or ketones, but direct hydroamination of alkynes with amines is $100 \%$ atom efficient and thermodynamically feasible hence can be used in domino reactions, where water is an undesired side product. Even though the hydroamination of alkynes is energetically more favorable, a high activation barrier exists [2]. Moreover, intermolecular processes are generally much more difficult to achieve and far less developed than intramolecular processes. Several different types of homogeneous catalysts have been reported for hydroamination reactions of alkynes [3]. Compared with homogeneous catalysts, only a handful of heterogeneous catalysts have been reported. Penzien et al. developed metal-exchanged zeolites for alkyne hydroamination, which favors Markovnikov addition products [4-7]. Pd complex immobilized on silica has been reported for intramolecular cyclization of amino-alkynes [8].

Heteropolyacids (HPA) and their salts are effective catalysts for various organic transformations such as acidcatalyzed reactions and oxidation [9-14]. They are highly effective heterogeneous catalysts for the gas-phase selective oxidation of organic substrates [15-17]. It has been reported that metal and organic salts of heteropoly acids are more active or product selective than their acid form in some organic transformations $[18,19]$. Heteropoly compounds with Keggin-type structure possess special characteristics that make them very active in catalytic reaction [13]. These also possess good reoxidativity of the catalyst by air and mobility of lattice oxygen, which are necessary for high activity. The

*Address correspondence to this author at the Inorganic Chemistry \& Catalysis Division, National Chemical Laboratory, Pune-411 008, India; Tel: +91-20-25902107; Fax: +91-20-25902633; E-mail: sb.halligudi@ ncl.res.in solubility of these compounds in turn is closely connected to their ability to absorb various reactants during the reaction. Nonpolar molecules are absorbed on the surface of bulk HPAs, while most polar molecules are mainly absorbed in the bulk, forming what Misono has described as a "pseudoliquid" phase [20]. This characteristics leads to two typical catalytic reaction types involving heteropoly compounds: surface-type and bulk-type reactions.

The use of heteropoly compounds as homogenous catalysts has its own drawbacks including recovery and recyclability issues and hence lot of effort has been made to heterogenise HPAs [21-27]. Most of the heteropoly salts are insoluble in non-polar solvents such as benzene, toluene and hydrocarbons and these are known to act as catalysts even in insoluble reaction medium [28-33]. Copper salts of HPA (CuHPA) have been used in some organic transformations [34-38]. Copper salt of silicotungstic acid (CuSTA) has been used as a catalyst in hydroxylation of phenol [39]. There is only one report in the literature on the application of heteropoly salts in hydroamination reactions where silver heteropoly salt has been used in the intermolecular hydroamination of alkynes [40].

In earlier studies, we have reported metal exchanged montmorillonite clays and CuAlSBA-15 for intermolecular hydroamination of terminal alkynes with aromatic amines [41-44]. The present work deals with the application of copper salts of heteropoly acids as heterogeneous catalysts in the liquid-phase intra and intermolecular hydroamination reactions to synthesize imines.

\section{RESULTS AND DISCUSSION}

\section{Catalytic Activities of Different HPAs and their Salts}

All catalysts were prepared by ion exchange of HPAs with aqueous transition metal acetate or carbonate solutions under identical conditions. These catalysts were used as heterogeneous catalysts in hydroamination of alkynes with amines since they are insoluble in nonpolar reaction medium. The reaction of phenylacetylene (hereafter referred as $\mathrm{PhAc}$ ) with aniline to give $\mathrm{N}$ - (methylbenzylidene) aniline was used as a model reaction. The reaction was carried out by taking heteropoly acids TPA, MPA and STA as catalysts. 
These acids showed very poor activities ( $>4 \%$ ) towards hydroamination even after $20 \mathrm{~h}$ reaction (Table 1). Activities of different copper salts of HPAs were compared after $1 \mathrm{~h}$ of reaction. CuSTA gave highest yield $(35 \%)$ followed by CuTPA $(28 \%)$ and CuMPA (27\%). The higher activity of CuSTA compared to neat HPAs suggests that copper is the active species in hydroamination reactions. The higher activity of CuSTA could be attributed to its higher copper content viz. 2 moles of copper in each mole of CuSTA salt compared to 1.5 moles of copper in CuTPA and CuMPA. The role of copper was further explored by conducting reaction with $\mathrm{Cu}_{1} \mathrm{H}_{2} \mathrm{STA}$, which showed almost half of the activity $(21 \%$ in 1h) compared to CuSTA. Other copper salts such as copper acetate and basic copper carbonate did not show any activity as heterogeneous catalysts. $\mathrm{Cu}^{2+}$ in these salts are so strongly bound with the anion that they cannot take part in the reaction whereas copper ion in heteropoly salts are loosely bound to the bulky Keggin anion, which enabled the reaction to catalyze heterogeneously.

Table 1. Catalytic Activities of Different Catalysts in Hydroamination of PhAc with Aniline

\begin{tabular}{|c|c|c|}
\hline Catalyst & Time (h) & PhAc Yield $(\%)^{*}$ \\
\hline TPA & 20 & 4 \\
\hline STA & 20 & 3 \\
\hline MPA & 20 & 3 \\
\hline CuSTA & 1 & 35 \\
\hline CuSTA & 8 & 99 \\
\hline $\mathrm{Cu}_{1} \mathrm{H}_{2} \mathrm{STA}$ & 1 & 21 \\
\hline CuTPA & 1 & 28 \\
\hline CuTPA & 8 & 99 \\
\hline CuMPA & 1 & 27 \\
\hline CuMPA & 8 & 99 \\
\hline ZnSTA & 8 & 45 \\
\hline PdSTA & 20 & 21 \\
\hline CoSTA & 20 & 8 \\
\hline NiSTA & 20 & 6 \\
\hline MnSTA & 20 & 5 \\
\hline $\mathrm{CuCO}_{3} \cdot \mathrm{Cu}(\mathrm{OH})_{2}$ & 20 & no reaction \\
\hline $\mathrm{Cu}\left(\mathrm{CH}_{3} \mathrm{COO}\right)_{2}$ & 20 & no reaction \\
\hline
\end{tabular}

*Yield is determined by GC analysis.

In order to find the influence of different transition metals on the intermolecular hydroamination of PhAc by aniline, silicotungstic salt prepared with different divalent transition metals such as $\mathrm{Zn}, \mathrm{Cu}, \mathrm{Pd}, \mathrm{Co}$, Mn were tested and the results are presented in Table 1. It is seen that CuSTA showed the highest activity and gave $99 \%$ yield while ZnSTA gave $45 \%$ yield in $8 \mathrm{~h}$. The other catalysts followed as PdSTA $(21 \%)>\operatorname{CoSTA}(8 \%)>\operatorname{MnSTA}(6 \%)$ after $20 \mathrm{~h}$ of reaction.

\section{Reactions of Different Alkynes and Amines}

CuSTA was used as catalyst to know the effect of nature of substituents on the aromatic ring of aniline derivatives over the reactivity (Table 2 . (A)). The electron-donating groups at the -meta and -Para positions gave higher yield for corresponding imines whereas substrates with electron withdrawing groups gave lower yield.

The sterically hindered amines such as 2,4,6-trimethylaniline $(75 \%)$ and 2, 4-xylidine $(80 \%)$ showed less reactivity. The amines with electron withdrawing substituents such as 4-chloroaniline (22\%), 4-bromoaniline $(34 \%)$ was least reactive. Interesting correlation of aromatic amine reactivity can be made with its basicity. It is observed that amine reactivity decreased with decrease in its basicity (Fig. 1). $p$ Anisidene $(\mathrm{pKb}=8.7)$ gave $89 \%$ yield after $4 \mathrm{~h}$ whereas 4 nitroaniline $(\mathrm{pKb}=13)$ did not undergo reaction. Amine, being a nucleophile, should be strong enough to attack the electron deficient carbon of alkynes (Scheme 3). Higher the basicity greater is the strength of the nucleophile.

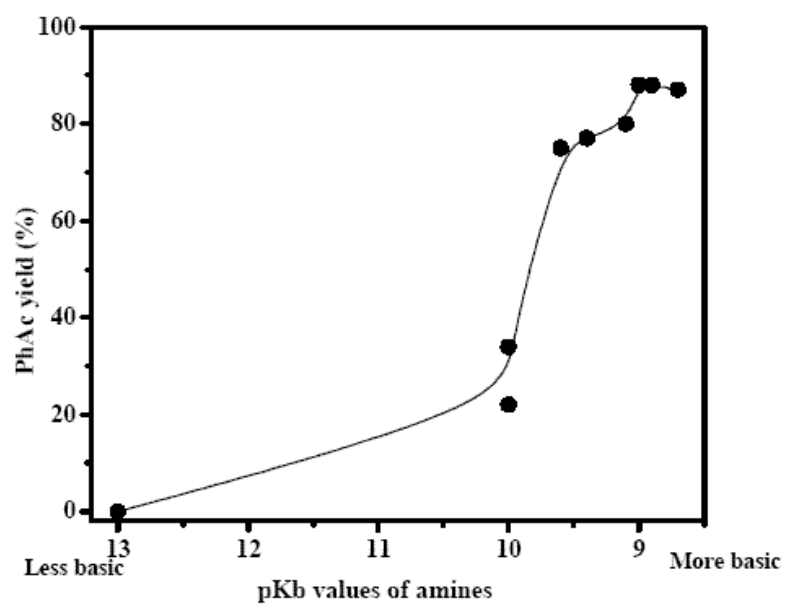

Fig. (1). Correlation between the yield of corresponding imines and the basicity of aromatic amines.

The reactions were also carried out by reacting different alkynes with aniline (Table 2. (B)). Aromatic alkynes were more reactive than aliphatic alkynes while terminal alkynes gave higher yield. Internal alkynes like diphenylacetylene did not undergo the reaction indicating that this catalyst is only suitable for hydroamination of terminal alkynes. The alkynes with electron-donating substituents, $-\mathrm{CH}_{3}$ and $\mathrm{OCH}_{3}$ gave better yield (80 and $91 \%$ after $4 \mathrm{~h}$ respectively) whereas the larger molecule like 1-ethynyl-6-methoxynaphthalene gave comparatively lower yield ( $76 \%$ after $8 \mathrm{~h}$ ). The reaction of aniline with 4-ethynylbenzaldehyde gave $50 \%$ yield for hydroamination product. The second product formed was due to the condensation of - $\mathrm{CHO}$ group with $\mathrm{NH}_{2}$ of aniline to form an imine. 4-Ethynylnitrobenzene yielded only $38 \%$ of product after $8 \mathrm{~h}$ of reaction. CuSTA catalyst can also be used effectively in intramolecular hydroamination of 6-amino-1-hexyne. The reaction gave 1,2dehydropiperidine with $99 \%$ yield.

Application of Solid Acids as Promoters Activities of CuSTA Supported on High Surface Area Mesoporous Silica (SBA-15) in Hydroamination Reaction.

The effect of impregnation of CuSTA on mesoporous SBA-15 and AlSBA-15 ( $\mathrm{Si} / \mathrm{Al}=17)$ was studied in hydroamination of $\mathrm{PhAc}$ with aniline in molar ratio of 1 , at 
Table 2. Hydroamination of Different Alkynes and Amines

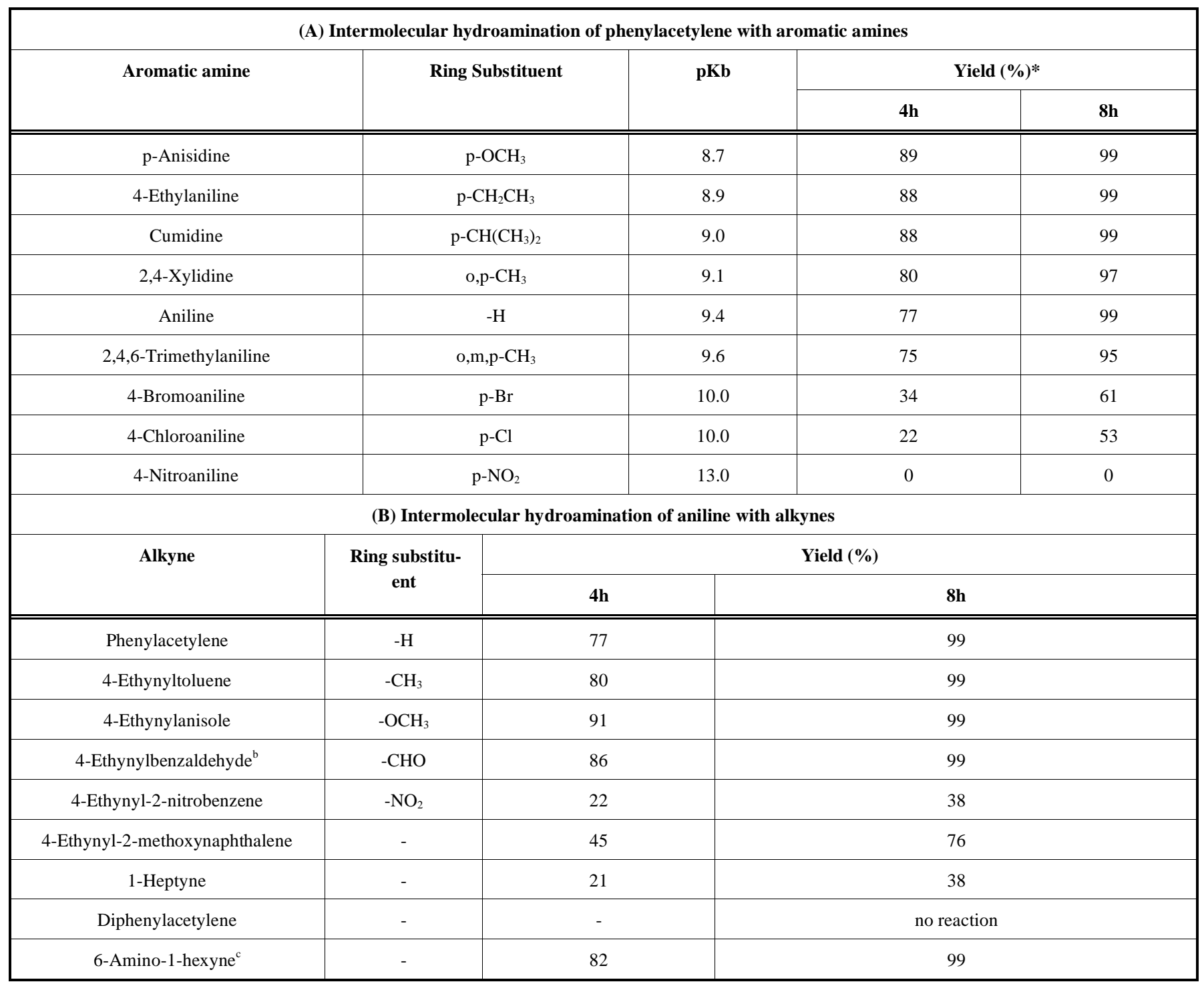

${ }^{\mathrm{a}}$ Conditions: catalyst $=\mathrm{CuSTA}$ Amine to alkyne mole ratio $=2$, toluene $=3 \mathrm{ml}$, temperature $=110{ }^{\circ} \mathrm{C}$, catalyst wt. $=0.3 \mathrm{~g}$, total reactants wt. $=2 \mathrm{~g}, *$ Yield is determined by $\mathrm{GC}$ analysis, $100 \%$ selectivity for Markovnikov product.

${ }^{\mathrm{b}} 55 \%$ selectivity for Markovnikov product.

'Intramolecular hydroamination; conditions: catalyst $=$ CuSTA, catalyst wt. $=0.075 \mathrm{~g}$ substrate wt. $=0.5 \mathrm{~g}$, temp $=110^{\circ} \mathrm{C}$, toluene $=2 \mathrm{ml}$.

$110^{\circ} \mathrm{C}$, using toluene as solvent. $20 \mathrm{wt} \%$ of CuSTA was impregnated on SBA-15 and AlSBA-15 to test the activities in hydroamination reaction. The amount of CuSTA loading was not optimized and was taken arbitrarily. The catalysts weight was adjusted in these reactions to keep CuSTA content constant for comparison of the activities with neat CuSTA salt. For example, $0.1 \mathrm{~g}$ of neat CuSTA was used in the reaction whereas $0.5 \mathrm{~g}$ of 20CuSTA/SBA-15 is used for comparison. Fig. (2) represents the time plots of neat and impregnated catalysts in hydroamination of PhAc with aniline. The reaction proceeded with $100 \%$ selectivity for Markovnikov addition product. SBA-15 and AlSBA-15 catalysts gave very low yield (2\% and 5\% respectively). When 20CuSTA/SBA-15 was used, the yield dropped by $10 \%$ compared to CuSTA after $8 \mathrm{~h}$ of reaction. The decrease in yield after CuSTA impregnation on SBA-15 suggests that the higher surface area of the support has no positive effect on the activity whereas a small decrease in yield may be attributed to a decrease in accessibility of the active sites after impregnation. On the other hand, 20CuSTA/A1SBA-15 catalysts showed about 2.5 times higher activity compared to CuSTA. The acidity present in AlSBA-15 possibly acts as a promoter in hydroamination of PhAc with aniline. Similar observation was made by T.E. Muller and co-workers when they found an enhancement in activity of $\mathrm{Zn}(\mathrm{OTf})_{2}$ by using triflic acid (a Brönsted acid) as a promoter in homogeneous intramolecular hydroamination reactions [45]. But the use of such strong homogeneous acids as promoters could lead to the leaching of active sites in heterogeneous catalysts. Hence the solid acids such as AlSBA-15 can prove as good promoters for $\mathrm{CuSTA}$ catalyst in hydroamination reaction.

\section{Catalyst Leaching, Regeneration and Recyclables Studies}

In order to check the leaching of active species from CuSTA into the reaction medium during hydroamination reaction, the reaction mixture was filtered while hot after $2 \mathrm{~h}$ of the reaction. The reaction was continued with the filtrate 
for $10 \mathrm{~h}$. The yield remained same even after $10 \mathrm{~h}$ of reaction, which indicates that no active species is leached into the reaction medium.

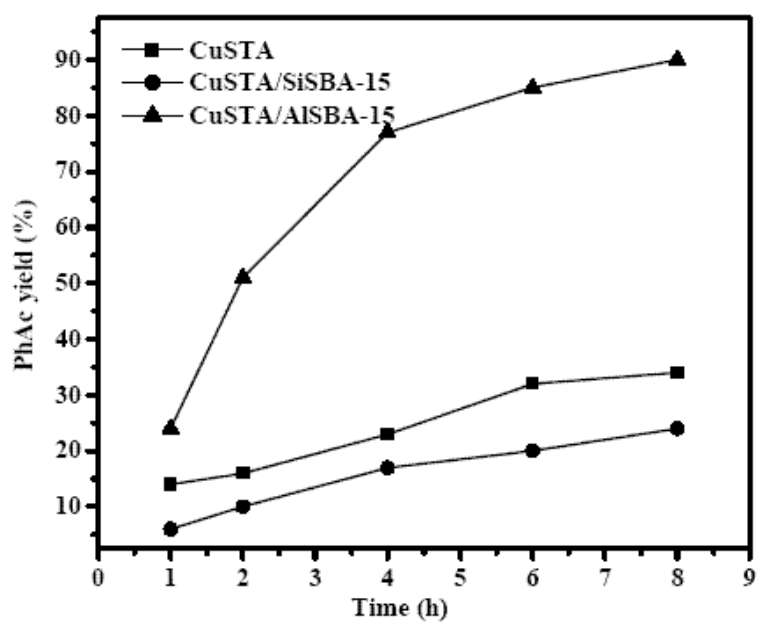

Fig. (2). Effect of support on the activity of the catalyst in hydroamination of $\mathrm{PhAc}$ by aniline.

Conditions: $\left(\right.$ temperature $=110^{\circ} \mathrm{C}$, aniline to $\mathrm{PhAc}$ mole ratio $=1$, catalyst wt. $=0.1 \mathrm{~g}$, total reactants wt. $=2 \mathrm{~g}$, toluene $=3 \mathrm{ml}$ ).

CuSTA catalyst, which gave highest yield, was separated from the reaction mixture and washed with toluene several times to remove adsorbed reactants and products. The catalyst was further refluxed in toluene for $2 \mathrm{~h}$, filtered and washed with toluene. The catalyst was then dried and calcined at $250^{\circ} \mathrm{C}$ for $5 \mathrm{~h}$. This regenerated catalyst was then used for first recycle. After every recycle, the regeneration procedure was repeated and used for the next recycle. It is observed that after 5 recycles of CuSTA catalyst, the yield of $\mathrm{PhAc}$ decreased by $12 \%$ (Table 3). The decrease in activity is due to the progressive deactivation of the catalyst.

Table 3. Catalyst Recylebility Study

\begin{tabular}{|c|c|}
\hline Cycle & Yield (\%) $^{*}$ \\
\hline \hline $1^{\text {st }}$ & 99 \\
\hline $2^{\text {nd }}$ & 95 \\
\hline $3^{\text {rd }}$ & 93 \\
\hline $4^{\text {th }}$ & 91 \\
\hline $5^{\text {th }}$ & 87 \\
\hline
\end{tabular}

\section{Plausible Mechanism}

The above results show that $\mathrm{Cu}^{2+}$ ion is the active site in CuSTA catalyst for hydroamination reaction. Activity of a particular metal depends on the hardness property of metal cation [5]. $\mathrm{Cu}^{2+}$ ion is moderately hard acid and hence shows very high activity for hydroamination compared to other metals. The plausible mechanism involves the nucleophilic addition of amine to alkyne coordinated to $\mathrm{Cu}^{2+}$ ion. Alkyne forms a $\pi$-coordination complex with copper in step 1 (Scheme 3). Amine attacks the electron deficient carbon atom on alkyne to form $\beta$-ammonioalkenyl complex in step 2. 1,3-Proton shift from nitrogen to $\beta$-carbon results in the formation of enamine in step 3 . Enamine being unstable under the reaction conditions, rearranges itself to form imine in step 4. Brönsted acidity can facilitate step 3 and step 4 where migration of protons is involved.

\section{CONCLUSIONS}

Hydroamination of alkynes with amines catalyzed by copper salt of heteropoly acid is a simple method to prepare imines. Copper exchanged STA shows the highest activity compared to other salts of heteropoly acids. Markovnikov addition product was formed with $100 \%$ selectivity. The aromatic amines with electron-donating substituents at the meta and -para positions gave higher imine yields whereas substrates with electron withdrawing or bulkier groups gave lower yields. The reactivity of amine increases with its basicity. Acidity in the heterogeneous catalyst acts as a promoter. CuSTA is an environmentally friendly, inexpensive and reusable heterogeneous catalyst, which can be used efficiently for hydroamination of terminal alkynes with aromatic amines.

\section{EXPERIMENTAL}

\section{Chemicals and Reagents}

All alkynes were purchased from Aldrich. Amines, $\mathrm{Cu}\left(\mathrm{CH}_{3} \mathrm{CO}_{2}\right)_{2}$ and toluene were purchased from Rankem, Mumbai, India. All the chemicals were used as received. Dry toluene was prepared by distilling and storing over sodium wire. 6-Amino-1-hexyne was prepared from the reduction of 5-cyanopent-1-yne using the procedure described elsewhere [46].

\section{Catalyst Preparation}

\section{$M^{n+} \boldsymbol{H P A}$}

Stoichiometric amounts of metal carbonates and HPA were used for the synthesis of copper salts of HPAs [47]. In a typical synthesis of $\mathrm{Cu}_{2} \mathrm{SiW}_{12} \mathrm{O}_{40}, 10 \mathrm{~g}$ (2.6 mmole) of $\mathrm{H}_{4}\left[\mathrm{SiW}_{12} \mathrm{O}_{40}\right] .28 \mathrm{H}_{2} \mathrm{O}$ was dissolved in $20 \mathrm{ml}$ of water and $0.58 \mathrm{~g}$ (2.6 mmole) of $\mathrm{CuCO}_{3} \cdot \mathrm{Cu}(\mathrm{OH})_{2}$ was added to the acid solution. Since no apparent evolution of gas occurred after the addition of the carbonate, the mixture was heated slowly to $65{ }^{\circ} \mathrm{C}$, which lead to evolution of carbon dioxide. The reaction mixture was then stirred for $0.5 \mathrm{~h}$ with cooling and filtered. A solid was obtained upon evaporation of the solution to dryness in the open. Then it was calcined to $250{ }^{\circ} \mathrm{C}$ for 5h. Similarly, $\mathrm{Cu}_{1} \mathrm{H}_{2} \mathrm{SiW}_{12} \mathrm{O}_{40}\left(\mathrm{Cu}_{1} \mathrm{H}_{2} \mathrm{STA}\right)$ was prepared by using appropriate amount of copper in the procedure (Scheme 1). The similar procedure was followed for the synthesis of copper salts of $\mathrm{H}_{3}\left[\mathrm{PW}_{12} \mathrm{O}_{40}\right]$ and $\mathrm{H}_{3}\left[\mathrm{PMo}_{12} \mathrm{O}_{40}\right]$. Similarly, Mn, Co, Ni, Pd and $\mathrm{Zn}$ salts of silicotungstic acid catalysts were prepared by employing similar procedures to those used for copper salts by taking metal carbonate or metal acetate salts as precursors. All the catalysts were calcined at $250^{\circ} \mathrm{C}$.

\section{Preparation of 20 wt.\% CuSTA/SBA-15 and 20 wt.\% Cu- STA/ALSBA-15}

SBA-15 and AlSBA-15 ( $\mathrm{Si} / \mathrm{Al}=17)$ were synthesized as reported elsewhere $[44,48]$. CuSTA/SBA-15 and CuSTA/ AlSBA-15 were prepared by wet impregnation method. $1 \mathrm{~g}$ 


$$
\begin{gathered}
\mathrm{H}_{4} \mathrm{SiW}_{12} \mathrm{O}_{40}+\mathrm{CuCO}_{3} \cdot \mathrm{Cu}(\mathrm{OH})_{2} \longrightarrow \mathrm{Cu}_{2} \mathrm{SiW}_{12} \mathrm{O}_{40}+3 \mathrm{H}_{2} \mathrm{O}+\mathrm{CO}_{2}^{----(a)} \\
4 \mathrm{H}_{3} \mathrm{PW}_{12} \mathrm{O}_{40}+3 \mathrm{CuCO}_{3} \cdot \mathrm{Cu}(\mathrm{OH})_{2} \longrightarrow 2 \mathrm{Cu}_{3}\left[\mathrm{PW}_{12} \mathrm{O}_{40}\right]_{2}+9 \mathrm{H}_{2} \mathrm{O}+3 \mathrm{CO}_{2}^{----(b)} \\
4 \mathrm{H}_{3} \mathrm{PMO}_{12} \mathrm{O}_{40}+3 \mathrm{CuCO}_{3} \cdot \mathrm{Cu}(\mathrm{OH})_{2} \longrightarrow 2 \mathrm{Cu}_{3}\left[\mathrm{PMO}_{12} \mathrm{O}_{40}\right]_{2}+9 \mathrm{H}_{2} \mathrm{O}+3 \mathrm{CO}_{2}^{---} \text {(c) }
\end{gathered}
$$

Scheme 1. Preparation of heteropoly salts of copper.

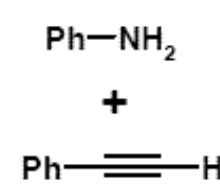

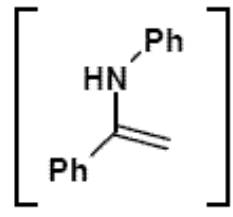

Enamine

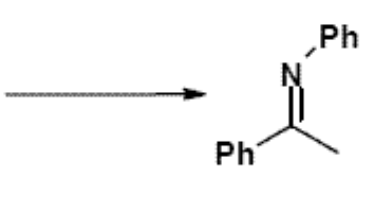

$\mathrm{N}$-(methylbenzylidene)aniline

Scheme 2. Intermolecular hydroamination of phenylacetylene with aniline.

of CuSTA (20 wt. \% of SBA-15) was dissolved in $25 \mathrm{ml}$ water. It was then added to $5 \mathrm{~g}$ of SBA-15 and stirred for $2 \mathrm{~h}$ at room temperature. Solvent was the evaporated on a rotary evaporator and resultant powder was dried and calcined at $250^{\circ} \mathrm{C}$ in static air. Similarly, the above procedure was followed for the preparation of $20 \mathrm{wt} \%$ CuSTA/AlSBA-15 (10).

\section{Experimental Procedure}

Experiments were carried out in a two-necked round bottom flask fitted with a water condenser connected to a balloon filled with $\mathrm{N}_{2}$ and kept in a thermostatic oil bath. Intermolecular hydroamination of $\mathrm{PhAc}$ with aniline is shown in Scheme 2. In a typical procedure, the reaction mixture containing phenylacetylene (0.66 g), 2,4,6-trimethylaniline (1.34 $\mathrm{g})$, toluene $(3 \mathrm{ml})$ and catalyst $(0.1 \mathrm{~g}$ catalyst calcined at 250 ${ }^{\circ} \mathrm{C}$ prior to use) was placed in the flask. The flask was then flushed twice with $\mathrm{N}_{2}$ before it was finally connected to balloon filled with $\mathrm{N}_{2}$ and the reaction was carried out at $110^{\circ} \mathrm{C}$ with constant stirring by a magnetic needle. Samples withdrawn at regular intervals of time were analyzed by gas chromatography (Shimadzu 14B) equipped with a crosslinked 5\% diphenyl-95\% dimethylpolysiloxane capillary column $(30 \mathrm{~m})$ and a flame ionization detector and the identity of the product was confirmed by FTIR(Shimadzu-8201 PC) and GCMS (Shimadzu GCMS QP5000) equipped with an identical column and a mass selective detector. The yield is determined by GC analysis. After 20hrs, the mixture was then cooled and filtered to remove the catalyst and the solvent was removed by distillation. The mixture was dried in

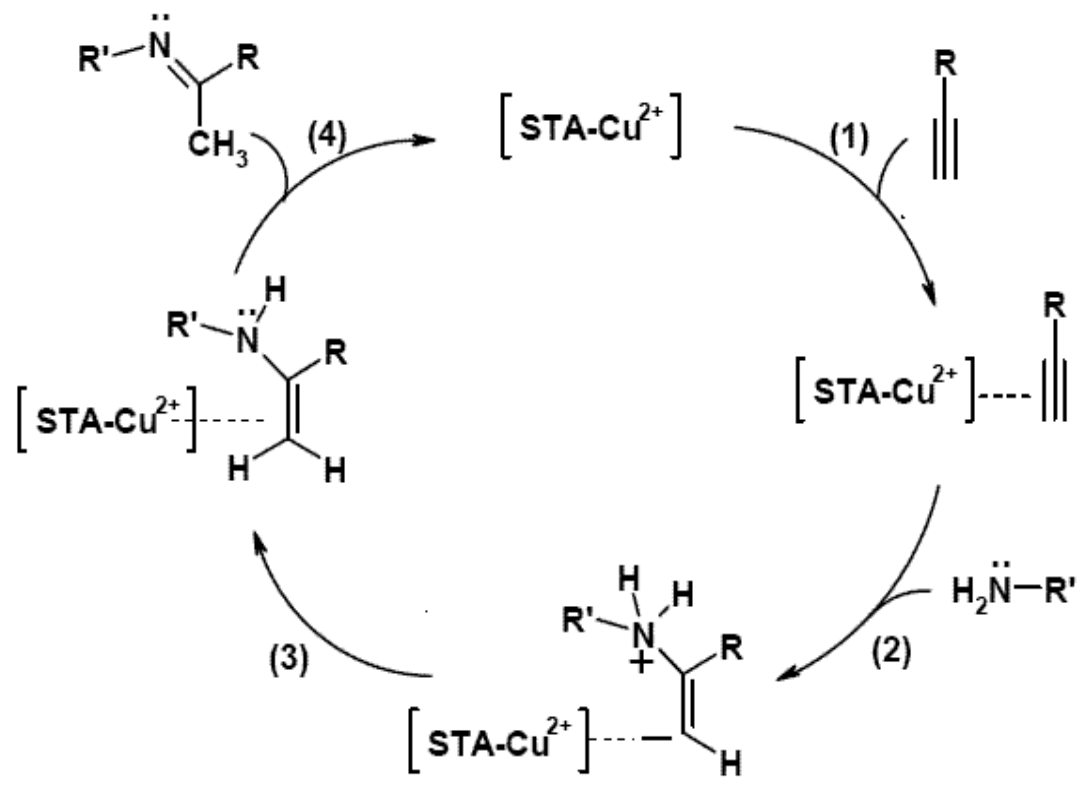

Scheme 3. Plausible mechanism of hydroamination of alkyne with amine catalyzed by CuSTA. 
vacuo and purified by column chromatography on neutral alumina as the stationary phase (petroleum ether/ethyl acetate, 200/1). Yield: $88 \%$, light brown oil: ${ }^{1} \mathrm{H} \mathrm{NMR}\left(\mathrm{CDCl}_{3}\right.$, $200 \mathrm{MHz}): \delta(\mathrm{ppm})=7.86-8.01(\mathrm{~m}, 2 \mathrm{H}), 7.31-7.48(\mathrm{~m}, 3 \mathrm{H})$, $6.80(\mathrm{~s}, 2 \mathrm{H}), 2.21(\mathrm{~s}, 3 \mathrm{H}), 1.99(\mathrm{~s}, 3 \mathrm{H}), 1.92(\mathrm{~s}, 6 \mathrm{H}) .{ }^{13} \mathrm{C}$ $\operatorname{NMR}\left(\mathrm{CDCl}_{3}\right): \delta(\mathrm{ppm})=165.5(\mathrm{C}), 146.5(\mathrm{C}), 139.3(\mathrm{C})$, $131.9(\mathrm{C}), 130.4(\mathrm{CH}), 128.5(\mathrm{CH}), 128.4(\mathrm{CH}), 127.1(\mathrm{CH})$, $125.6(\mathrm{C}), 20.8\left(\mathrm{CH}_{3}\right), 17.9\left(\mathrm{CH}_{3}\right), 17.4\left(\mathrm{CH}_{3}\right)$. FT IR (neat, $\left.\mathrm{cm}^{-1}\right): 3025,2940,1638,1207,1025,856,762,629$. GCMS $\mathrm{m} / \mathrm{z}$ (relative intensity): $237(64)\left[\mathrm{M}^{+}\right], 222$ (100), 207 (47), 103 (52), 91 (55), 77 (40).

\section{ACKNOWLEDGEMENTS}

G.V.S. acknowledges CSIR, New Delhi, for the award of Senior Research Fellowship.

\section{REFERENCES}

[1] Roundhill, M. D. Chem. Rev., 1992, 91, 1.

[2] Hartung, C. G.; Tillack, A.; Trauthwein, H.; Beller, M. J. Org. Chem., 2001, 66, 6339.

[3] Nobis, M.; Drießen-Hölscher, .B. Angew. Chem. Int. Ed., 2001, 40, 3983.

[4] Penzien, J.; Muller, T. E.; Lercher, A. J. Chem. Commun., 2000, 1753

[5] Penzien, J.; Haeßner, C.; Jentys, A.; Köhler, K.; Müller, T. E.; Lercher, J. J. Catal., 2004, 221, 302.

[6] Penzien, J.; Muller, T. E.; Lercher, A. J. Micropor. Mesopor. Mater., 2001, 48, 285.

[7] Penzien, J.; Su, R. Q.; Muller, T. E. J. Mol. Catal. A Chem., 2002, $182,489$.

[8] Richmond, M. K.; Scott, S. L.; Alper, H. J. Am. Chem. Soc., 2001, 123,10521

[9] Niiyama, H.; Saito, Y.; Echigoya, E. "Proceedings, 7th International Congress on Catalysis, Tokyo, 1980," Kodansha, Tokyo/Elsevier, Amsterdam, 1981; pp. 1416

[10] Hayashi, H.; Moffat, B. J. J. Catal., 1982, 77, 473.

[11] Okuhara, T.; Hashimoto, T.; Hibi, T.; Misono, M. J. Catal., 1985, 93, 224.

[12] Misono, M. Catal. Rev. Sci. Eng., 1987, 29, 269.

[13] Kozhevnikov, V. I. Chem. Rev., 1998, 98, 171.

[14] Crusson, B. E.; Rigole, M.; Fournier, M.; Aboukais, A.; Daubreged, F.; Hecquet, G.; Michel Guelton. Appl. Catal. A Gen., 1999, 178,69 .

[15] Kim, S. J.; Kim, M. J.; Seo, G.; Park, C. N.; Niiyama, H. Appl. Catal. A Gen., 1988, 37, 45.

[16] Izumi, Y. Catal. Today, 1997, 33, 371.

[17] Mizuno, N.; Misono, M. Chem. Rev., 1998, 98, 199.

[18] Ono, Y.; Baba, Y.; Sakai, J.; Keii, T. J. Chem. Soc. Chem. Commun., 1982, 400.

[19] Okuhara, T.; Hayakawa, N.; Kasai, A.; Misono, M.; Yoneda, Y. J. Catal., 1992, 74, 121

[20] Misono, M. J.; Okuhara, T.; Ichiki, T.; Arai, T.; Kanda, Y.J. Am. Chem. Soc., 1987, 109, 5535.
[21] Aboukais, A.; Ghoussoub, G.; Crusson, E. B.; Rigole, M.; Guelton. M. Appl. Catal. A Gen., 1994, 111, 109.

[22] Tatibouet, M. J.; Montalescot, C.; Bruckman, K. Appl. Catal. A Gen., 1996, 138, 11.

[23] Damyanova, S.; Fierro, J. L. G. Chem. Mater., 1998, $10,871$.

[24] Molnár, A.; Beregszászi, T.; Fudala, A.; Lentz, P.; Nagy J. B.; Konya, Z.; Kiricsi, I. J. Catal., 2001, 202, 379.

[25] Yuan, C.; Zhang, F.; Wang, J.; Ren, X. Catal.Commun., 2005, 6, 721.

[26] Reddy, K. M.; Lingaiah, N.; Prasad, P. S. S.; Suryanarayana, I. J. Sol. Chem., 2006, 35, 407.

[27] Gu, Y. B.; Wei, R. P.; Ren X. Q.; Wang, J. Catal. Lett., 2007, 113, 41.

[28] Okuhara, T.; Nishimura, T.; Watanabe, H.; Misono, M. J. Mol. Catal. A Chem., 1983, 74, 247.

[29] McGarvey, G. B.; Moffat, B. J. Catal. Lett., 1992, 16, 173.

[30] Kreemers, A. W. S.; Zon, M. V. D.; Makkee, M.; Scholten. J. J. F. J. Mol. Catal. A Chem., 1996, 107, 247.

[31] Nowinska, K.; Sopa, M.; Dudko, D.; Mocna, M. Catal. Lett., 1997, $49,43$.

[32] Rocha, K. A. S.; Dutenhefner, P.A.R.; Sousa, E. M. B.; Kozhevnikova, E. F.; Kozhevnikov, I.V.; Gusevskaya, E.V. Appl. Catal. A Gen., 2007, 317, 171.

[33] Giri, B. Y.; Devi, B. L. A. P.; Gangadhar, K. N.; Lakshmi, K. V.; Prasad, R. B. N.; Lingaiah, N.; Prasad, P. S. S. Syn. Commun., 2007, 37, 2331.

[34] Crusson, E. B.; Rigole, M.; Fournier, M.; Aboukaões, A.; Daubrege, F.; Hecquet,G.; Guelton, M. Appl. Catal. A Gen., 1999, 178,69 .

[35] Alekar, N. A.; Gopinathan, S.; Gopinathan, C. Ind. J. Chem. A, 2000, 39, 439.

[36] Aouissi, A.; Allaoui, L. A.; Aldhayan, D. Asian J.Chem., 2006, 18, 3009.

[37] Allaoui, A. L.; Aaouissi, A. J. Mol. Catal. A Chem., 2006, 259, 281.

[38] Zhou, G.; Yang, X.; Liu, J.; Zhen, K.; Wang, H.; Cheng, T. J. Phys. Chem. B, 2006, 110, 9831 .

[39] Zhang, H.; Zhang, X.; Ding. Y.; Yan, L.; Ren, T.; Suo, J. New J. Chem., 2006, 26, 376 .

[40] Lingaiah, N.; Babu, N. S.; Reddy, M. K.; Prasad, P. S. S.; Suryanarayana, I. Chem. Commun., 2007, 278.

[41] Shanbhag, G. V.; Halligudi, S. B. J. Mol. Catal. A Chem., 2004, $222,223$.

[42] Joseph, T.; Shanbhag, G. V.; Halligudi, S. B. J. Mol. Catal. A Chem., 2005, 236, 139.

[43] Shanbhag, G. V.; Kumbar, S. M.; Joseph, T.; Halligudi, S. B. Tetrahedron. Lett., 2006, 47, 141 .

[44] Shanbhag, G. V.; Joseph, T.; Halligudi, S. B. J. Catal., 2007, 250 , 274.

[45] Penzien, J.; Su, R. Q.; Muller, T. E. J.Mol. Catal. A Chem., 2002 182,489

[46] Muller, T.; Elercher, J. A.; Nhu, N. V. AIChE, 2003, 49, 214.

[47] Tsigdinos, G. A. Ind. Eng. Chem. Prod. Res. Dev., 1974, 13, 267.

[48] Zhao, D.; Feng J.; Huo, Q.; Melosh, N.; Fredrickson, G. H.; Chmelka, B. F.; Stucky, G. D. Science, 1998, 279, 548. 